\title{
Medical Students' Views of Medicine as a Calling and Selection of a Primary Care-Related Residency
}

\author{
Audiey C. Kao, MD, PbD \\ Andrew J. Jager, MA \\ American Medical Association, \\ Chicago, Illinois
}

\begin{abstract}
With the US health care system facing a primary care physician shortage, we evaluated whether medical students who saw medicine as a calling were more likely to enter a family medicine, internal medicine, or pediatrics residency program. Of the 591 4th-year medical students who responded to a survey item on medicine as a calling, 237 strongly agreed that the "practice of medicine is a calling." Students who strongly agreed that medicine was a calling had higher odds $(P=.003)$ of selecting a primary care-related residency. Identifying with medicine as a calling may increase the likelihood of pursuing a primary care career.

Ann Fam Med 2018;16:59-61. https://doi.org/10.1370/afm.2149.

\section{INTRODUCTION}

T he practice of medicine has long been appreciated as a calling defined as a commitment to work that is personally meaningful and serves a prosocial purpose. ${ }^{1}$ With a projected shortage of upwards of 43,000 primary care physicians by $2030,{ }^{2}$ no studies, to our knowledge, have examined whether medical students' views of medicine as a calling influence their residency specialty choice. In the study described herein, we evaluated whether medical students who identify with medicine as a calling are more likely to pursue a residency in family medicine, internal medicine, or pediatrics, which is the pipeline for the primary care physician workforce.
\end{abstract}

\section{METHODS}

As part of a broader research initiative on physician work motivation, the survey protocol designed to assess medical students' vocational views and educational experiences was deemed exempt by the Office for the Protection of Research Subjects, University of Illinois at Chicago. Using the American Medical Association (AMA) Physician Masterfile, we selected a random sample of 1,000 4th-year allopathic and osteopathic medical students. Between October 2014 and May 2015, we conducted 3 rounds of a self-administered mail survey with a $\$ 2$ bill included in the second round to encourage participation. Subsequent to the mailings, 127 students were found study ineligible because the questionnaires were returned as undeliverable or they were no longer in medical school.

Students' age, sex, race or ethnicity, medical school, and graduate medical education (GME) specialty were derived from the AMA Physician Masterfile. GME specialty data were obtained 18 months into respondents' residency. For the survey questionnaire, we used a validated single-item measure of sense of calling to medicine, "For me, the practice of medicine is a calling,"3 with a 5-point Likert agree-disagree response scale. Missing GME specialty data were supplemented by queries on medical residency program websites using respondents' names and medical school alma maters. GME specialty data were unavailable for 37 respondents because some students, for example, were still completing dual degrees in medical school or decided to not pursue residency training.
Audiey C. Kao, MD, PhD

American Medical Association 330 N. Wabash Ave

Chicago, IL 60611

audiey.kao@ama-assn.org 
We assessed differences between respondents and nonrespondents in terms of age using the $t$ test and in terms of sex, race or ethnicity, and medical school social mission rank ${ }^{4}$ (as determined by percentage of graduates who practice primary care, work in health professional shortage areas, and are underrepresented minorities) with the Pearson $\chi^{2}$ test. Association between students' views of medicine as a calling and primary care-related residency was assessed using logistic regression in which the dependent variable was specified as medical students who entered a family medicine, internal medicine, pediatrics, or combined internal medicine/pediatrics residency program. Other regression model covariates were students' personal demographics and medical school social mission rank.

\section{RESULTS}

Survey response rate was $68 \%$ ( $N=591$ respondents). There was no significant difference in age, sex, and medical school social mission rank between respondents and nonrespondents. There were more white students in the respondent than the nonrespondent group (59\% vs $52 \%, P=.05)$. Most students saw the practice of medicine as a calling regardless of GME or residency specialty (Figure 1). Logistic regression revealed that those who strongly agreed that medicine was a calling had significantly greater odds of selecting a primary care-related residency (Table 1).

\section{DISCUSSION}

Driven by an aging population and insurance coverage expansion, the US health care system is confronting a major shortage of primary care physicians. ${ }^{1}$ Although efforts to increase the number of these physicians have focused on increasing the number of primary care residency positions and addressing the income gap between primary care and procedure-intensive specialties, ${ }^{5,6}$ our study points to a professional identity factor that merits some consideration-fostering or at least not undermining a sense of calling among future physicians. From a medical education perspective, professional identity is "a representation of self, achieved in stages over time during which the characteristics, values, and norms of the medical profession are internalized, resulting in an individual thinking, acting, and feeling like a physician." ${ }^{17}$ As such, professional identity formation that supports a career choice in primary care may require a learning environment where medical students are exposed to and interact with physicians who exemplify professionalism and a calling to the practice of medicine. ${ }^{8}$

Medical school culture may contribute to shaping students' specialty preferences. Students who attend medical schools where primary care is less respected (such as potentially those with low social mission scores) are less likely to pursue a career in primary care. ${ }^{9}$ On the other hand, the likelihood of choosing a primary care specialty increases when medical students have positive experiences in primary care clerkships ${ }^{9}$ and greater exposure to generalist role models. ${ }^{10}$ Because preclinical medical students who are interested in primary care have been found to identify more with medicine as a calling, ${ }_{1}^{11}$ exposing students to generalist role models as early as possible may be particularly important in translating specialty preference to career choice.

Another consideration to fostering a medical school culture that sustains students' sense of calling may be to address the undue stressors and demands that their

\section{Figure 1. Medical students' views of medicine as a calling by} graduate medical education (GME) specialty.

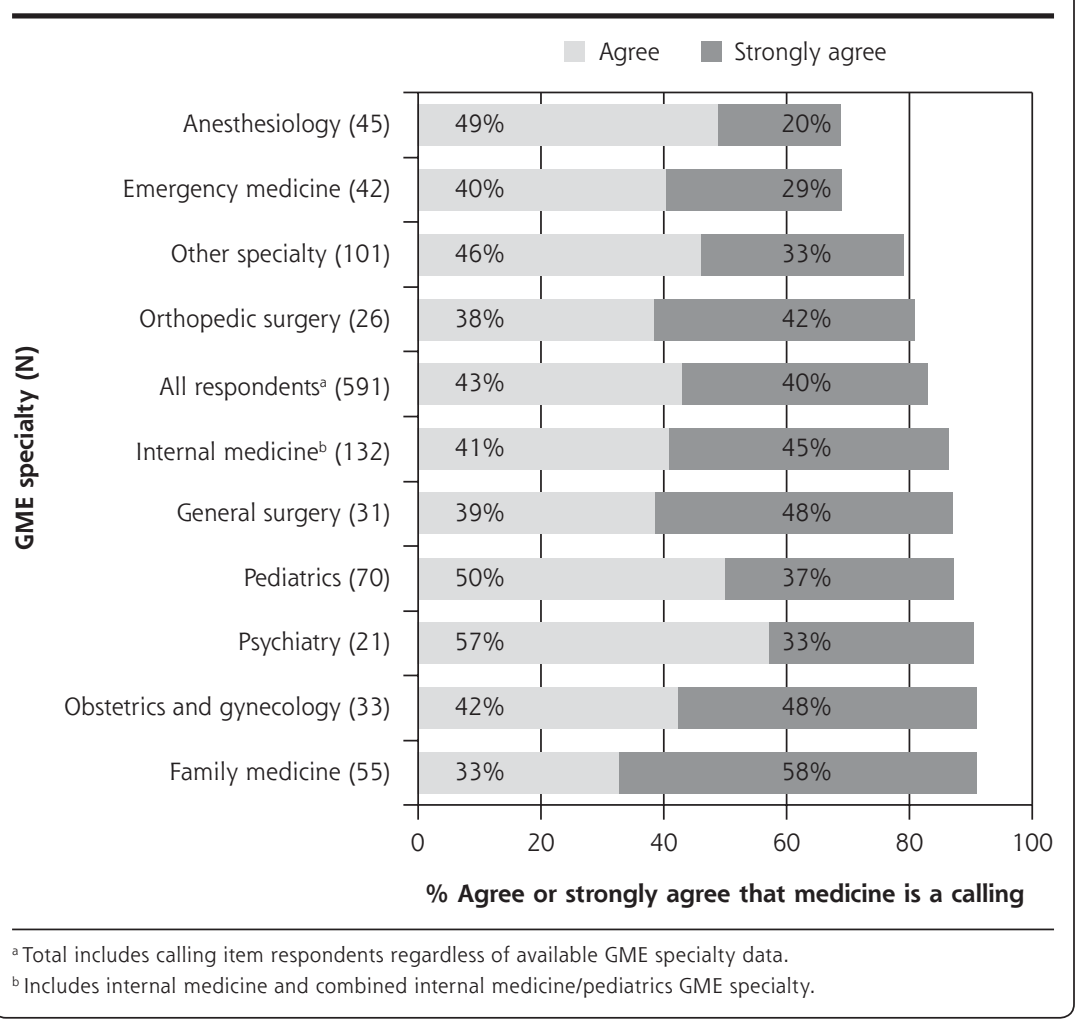




\section{Table 1. Odds of Selecting a Primary Care-Related Residency and the Medical Student's View of Medicine as a Calling, Personal Characteristics, and Medical School Social Mission Ranking}

\begin{tabular}{|c|c|c|c|c|c|}
\hline \multirow[b]{2}{*}{ Variable } & \multicolumn{5}{|c|}{ Primary Care-Related Residency $(\mathrm{n}=257$ ) } \\
\hline & $\begin{array}{l}\text { No. } \\
(\%)\end{array}$ & $\begin{array}{l}\text { Unadjusted } \\
\text { OR }(95 \% \mathrm{Cl})\end{array}$ & $\begin{array}{c}P \\
\text { Value }\end{array}$ & $\begin{array}{c}\text { Adjusted } \\
\text { OR ( } 95 \% \mathrm{Cl})\end{array}$ & $\begin{array}{c}P \\
\text { Value }\end{array}$ \\
\hline \multicolumn{6}{|l|}{$\begin{array}{l}\text { Practice of medicine is } \\
\text { a calling }\end{array}$} \\
\hline $\begin{array}{l}\text { Strongly disagree/ } \\
\text { disagree/neither } \\
\text { agree nor disagree }\end{array}$ & $32(34)$ & 1.00 [Reference] & $\cdots$ & 1.00 [Reference] & $\ldots$ \\
\hline Agree & $107(45)$ & $1.58(0.97-2.60)$ & .07 & $1.52(0.92-2.52)$ & .10 \\
\hline Strongly agree & $118(53)$ & $2.26(1.37-3.72)$ & .001 & $2.16(1.30-3.59)$ & .003 \\
\hline \multicolumn{6}{|l|}{ Personal characteristics } \\
\hline Male & $115(41)$ & $\ldots$ & $\ldots$ & 1.00 [Reference] & .08 \\
\hline Female & $142(51)$ & $\ldots$ & $\ldots$ & $1.36(0.96-1.93)$ & \\
\hline Non-white & $115(51)$ & $\ldots$ & $\ldots$ & 1.00 [Reference] & .06 \\
\hline White & $142(43)$ & $\ldots$ & $\ldots$ & $0.71(0.50-1.01)$ & \\
\hline Age $(y)$ & N/A & $\ldots$ & $\ldots$ & $0.97(0.91-1.03)$ & .33 \\
\hline \multicolumn{6}{|l|}{$\begin{array}{l}\text { Medical school social } \\
\text { mission rank }\end{array}$} \\
\hline $\begin{array}{l}\text { Low (20 schools with } \\
\text { lowest rank scores) }\end{array}$ & $24(34)$ & $\ldots$ & $\ldots$ & 1.00 [Reference] & \\
\hline Intermediate & $194(46)$ & $\ldots$ & $\ldots$ & $1.70(0.99-2.93)$ & .06 \\
\hline $\begin{array}{l}\text { High (20 schools with } \\
\text { highest rank scores) }\end{array}$ & $39(57)$ & $\ldots$ & $\ldots$ & $2.75(1.35-5.59)$ & .005 \\
\hline
\end{tabular}

Key words: physicians, primary care; health manpower; career choice

Submitted April 3, 2017; submitted, revised, May 24, 2017; accepted June 26, 2017.

Funding support: This study was funded by the American Medical Association.

Acknowledgments: The authors would like to thank Modena Wilson, MD, MPH and Alejandro Aparicio, MD, for their helpful comments on an earlier version of this article.

\section{References}

1. Dik BJ, Duffy RD. Calling and vocation at work: definitions and prospects for research and practice. Couns Psychol. 2009:37(3):424-445.

2. Inc IHS. 2017 Update: The Complexities of Physician Supply and Demand: Projections From 2015 to 2030: Final Report. Washington, DC: Association of American Medical Colleges; 2017. https://aameblack.global.ssl.fastly.net/production/ media/filer_public/a5/c3/a5c3d56514ec-48fb-974b-99fafaeecb00/aamc projections_update_2017.pdf

3. Rasinski KA, Lawrence RE, Yoon JD, Curlin FA. A sense of calling and primary care physicians' satisfaction in treating smoking, alcoholism, and obesity. Arch Intern Med. 2012;172(18) 1423-1424.

teachers - resident and attending physicians - face in the health care workplace. Higher physician burnout has been found to be associated with a lower sense of calling. ${ }^{12}$ With increased prevalence in physician burnout and its negative consequences on quality of patient care, individual- and organizational-level strategies designed to reduce burnout are garnering greater attention and urgency.$^{13}$ If these strategies are successful in reducing burnout, they may have the unintended benefit of ameliorating the primary care physician workforce shortage.

A key limitation of our study was that we assessed medical students' entry into a primary care-related residency, not whether respondents will practice primary care after residency. Although proportions of resident physicians likely to pursue a career in primary care have been found to vary across primary care GME specialties (eg, family medicine: 0.91 i internal medicine: 0.10 0.20 , pediatrics: 0.44$){ }_{1}^{14}$ studies that observe medical students after residency training are necessary to determine whether those who eventually practice primary care are more likely to have seen medicine as a calling.

With a projected primary care physician shortage, efforts aimed at sustaining future physicians' sense of calling may help to address these workforce needs.

To read or post commentaries in response to this article, see it online at http://www.AnnFamMed.org/content/16/1/59.
4. Mullan F, Chen C, Petterson S, Kolsky G, Spagnola M. The social mission of medical education: ranking the schools. Ann Intern Med. 2010;152(12):804-811.

5. Schumacher DJ, Frintner MP, Cull W. Relationships between program size, training experience, and career intentions: pediatrics resident reports from 2010 to 2014. Acad Pediatr. 2016;16(7):630-637.

6. Kruse J. Income ratio and medical student specialty choice: the primary importance of the ratio of mean primary care physician income to mean consulting specialist income. Fam Med. 2013;45(4):281-283.

7. Cruess RL, Cruess SR, Boudreau JD, Snell L, Steinert Y. Reframing medical education to support professional identity formation. Acad Med. 2014;89(11):1446-1451.

8. Cooke M, Irby DM, O'Brien BC. Educating Physicians: A Call for Reform of Medical School and Residency. San Francisco, CA: Jossey-Bass; 2010.

9. Erikson CE, Danish S, Jones KC, Sandberg SF, Carle AC. The role of medical school culture in primary care career choice. Acad Med. 2013;88(12):1919-1926.

10. Henderson MC, Hunt DK, Williams JW Jr. General internists influence students to choose primary care careers: the power of role modeling. Am J Med. 1996;101(6):648-653.

11. Borges NJ, Manuel RS, Duffy RD. Speciality interests and career calling to medicine among first-year medical students. Perspect Med Educ. 2013;2(1):14-17.

12. Jager AJ, Tutty MA, Kao AC. Association between physician burnout and identification with medicine as a calling. Mayo Clin Proc. 2017;92(3):415-422.

13. Shanafelt TD, Dyrbye LN, West CP. Addressing physician burnout: the way forward. JAMA. 2017;317(9):901-902.

14. Council on Graduate Medical Education. Twentieth Report: Advancing Primary Care. https://www.hrsa.gov/advisorycommittees/bhpradvisory/ cogme/Reports/twentiethreport.pdf. Published Dec 2010. 